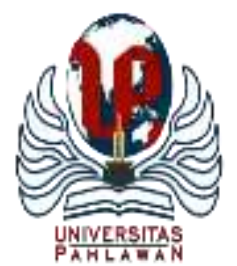

\title{
JURNALBASICEDU
}

Volume 6 Nomor 1 Tahun 2022 Halaman 499 - 505

Research \& Learningin Elementary Education

https://jbasic.org/index.php/basicedu

\section{Penerapan Media Pembelajaran Berbasis Macromedia Flash dalam Meningkatkan Kreativitas Siswa pada Mata Pelajaran Matematika di Sekolah Dasar}

\author{
Ari Aprilia Dwiana ${ }^{1 凶}$, Angela Samosir $^{2}$, Nauli Tama Sari ${ }^{3}$, Nur Awalia $^{4}$, Aan Budiyono ${ }^{5}$, \\ Molli Wahyuni ${ }^{6}$, Masrul $^{7}$
}

Program Studi Pendidikan Dasar, Universitas Pahlawan Tuanku Tambusai, Indonesia ${ }^{1,2,3,4,5,6,7}$

E-mail: ari.aprilia90@ gmail.com ${ }^{1}, \underline{\text { samosirangela63@ gmail.com }}^{2}, \underline{\text { naulitamasari56@gmail.com }}^{3}$, nurawalia.psp@gmail.com ${ }^{4}, \underline{\text { anbudiono055@gmail.com }}^{5}, \underline{\text { whykpr@gmail.com }}^{6}, \underline{\text { masrulm25@gmail.com }}^{7}$

\begin{abstract}
Abstrak
Penelitian ini bertujuan untuk untuk memperoleh informasi peningkatan kreativitas belajar siswa pada mata pelajaran Matematika dengan menggunakan media pembelajaran macromedia flash. Penelitian ini adalah penelitian deskriptif kualitatif yang mengumpulkan data secara naratif dalam bentuk kata-kata dari fenomena yang diteliti. Penelitian ini dilaksanakan di SD Negeri 013 Rambah dengan obyek yang adalah siswa kelas IV dengan jumlah siswa 25 orang. Pengumpulan data menggunakan metode observasi, wawancara, kuesioner dan dokumentasi. Berdasarkan hasil penelitian diketahui bahwa sebagian besar siswa sangat tertarik belajar menggunakan media pembelajaran khususnya macromedia flash. Hal ini dapat dilihat dari hasil observasi terhadap proses pembelajaran yang menunjukkan bahwa siswa lebih semangat dan antusias, serta aktif dan kreatif dalam belajar. Hal ini didukung oleh hasil interview dan kuesioner dengan siswa yang menjelaskan bahwa siswa sangat senang belajar menggunakan macromedia flash karena tampilannya yang menarik dan mudah dipahami.Kesimpulan dalam penelitian ini adalah terdapat peningkatan kreativitas siswa menggunakan media pembelajaran macromedia flash. Media pembelajaran macromedia flash ini dapat membantu guru dalam menyampaikan materi belajar dan mempermudah siswa dalam memahami materi pelajaran yang disampaikan sehingga kreativitas siswa dalam belajar meningkat.
\end{abstract}

Kata Kunci: Penerapan, Media Pembelajaran, Macromedia Flash, Kreativitas, Matematika

\begin{abstract}
This research aims to provide information on increasing students' creativity in by using macromedia flash media. This research is a descriptive qualitative research that collects narrative data in the form of words from the phenomenon under study. This research was conducted at SD Negeri 013 Rambah and the object was the fourth grade students with a total of 25 students. Collecting data using the method of observation, interviews, questionnaires and documentation. Based on the results of the research, it is known that most of the students are very interested in learning to use the learning media, especially Macromedia Flash. This can be seen from the results of observations of the learning process which shows that students are more enthusiastic, as well as active and creative in learning. This is supported by the results of interviews and questionnaires with students which explained that students are very happy to learn to use macromedia flash because it looks attractive and easy to understand. The conclusion in this research there is an increase in students' creativity using macromedia flash learning media. This macromedia flash learning media can assist teachers in delivering learning materials and make it easier for students to understand the subject presented so that students' creativity in learning increases.
\end{abstract}

Keywords:Application, Learning Media, Macromedia Flash, Creativity, Mathematics

Copyright (c) 2022 Ari Aprilia Dwiana, Angela Samosir, Nauli Tama Sari, Nur Awalia, Aan Budiyono, Molli Wahyuni, Masrul

$\checkmark$ Corresponding author :

Email : ari.aprilia90@gmail.com

DOI : https://doi.org/10.31004/basicedu.v6i1.1669 

pada Mata Pelajaran Matematika di Sekolah Dasar - Ari Aprilia Dwiana, Angela Samosir, Nauli Tama Sari, Nur Awalia, Aan Budiyono, Molli Wahyuni, Masrul

DOI: https://doi.org/10.31004/basicedu.v6i1.1669

\section{PENDAHULUAN}

Pendidikan sangat penting pada saat ini, karena pendidikan merupakan kebutuhan mutlak manusia yang harus dipenuhi sepanjang hayat. Pendidikan adalah upaya sadar untuk mempersiapkan peserta didik untuk peran mereka di masa depan melalui kegiatan orientasi, pengajaran, dan pelatihan (Lasmiyatun \& Saptaningrum, 2019). Proses pendidikan bukan hanya membentuk kecerdasan dan/atau memberikan keterampilan tertentu saja akan tetapi juga membentuk dan mengembangkan sikap agar anak berperilaku sesuai dengan norma-norma yang berlaku di masyarakat (Heri Setiawan \& Harta, 2014). Sekolah sebagai bentuk pendidikan formal memiliki banyak kegiatan penting dalam pendidikan, salah satunya adalah pembelajaran. Pembelajaran merupakan sebuah proses interaksi yang terjadi antara pendidik dan peserta didik (Johariyah \& Resti, n.d.). Sejalan dengan upaya mencerdaskan kehidupan bangsa, salah satu upaya yang dilakukan adalah peningkatan mutu pendidikan yang dapat ditempuh dengan melakukan perbaikan pada komponen pembelajaran di sekolah, termasuk pengembangan media pembelajaran.

Salah satu mata pelajaran yang selalu ada di semua jenjang pendidikan adalah matematika. Pembelajaran matematika sebaiknya memberikan kesempatan kepada siswa untuk berperan aktif membangun pengetahuannya (Rusnilawati, 2016). Berdasarkan pengamatan dan wawancara kepada guru kelas pada mata pelajaran matematika kelas IV di SD Negeri 013 Rambah, di peroleh gambaran bahwa kreativitas belajar siswa di kelas IV sangat rendah dengan ditandai oleh siswa cenderung monoton, pengetahuan siswa hanya terbatas pada apa yang diperoleh guru, siswa kesulitan dalam menegembangkan pengetahuan yang diperoleh dari pembelajaran, siswa kurang berani mengungkapkan ide, gagasan, atau pendapat.

Beberapa faktor yang termasuk dalam faktor sekolah antara lain adalah metode mengajar dan alat pelajaran atau media (Nurhayati et al., 2013). Media ialah seluruh suatu yang bisa mengantarkan pesan dari sesuatu informasi secara teratur, sehingga terjalin area belajar yang kondusif (Rahmat Dian et al., 2020). Media pembelajaran adalah yaitu alat yang dapat membantu proses belajar mengajar dan berfungsi untuk memperjelas makna pesan yang disampaikan, sehingga dapat mencapai tujuan pembelajaran dengan lebih baik dan sempurna (Hutomo, 2015). Media Pembelajaran adalah alat yang secara fisik digunakan untuk menyampaikan isi materi pengajaran, yang terdiri dari antara lain buku, tape-recorder, kaset, video camera, film side, foto, gambar, grafik, televisi dan komputer. Media pembelajaran yang dimaksud dalam penelitian ini adalah suatu media alat bantu dalam proses perkuliahan berupa tampilan dalam komputer yang dibuat dengan aplikasi macromedia flash 8 (Nursofi, Muhammad Faiq, 2011). Media pembelajaran adalah merupakan factor yang mendukung keberhasilan proses pembelajaran di sekolah karena dapat membantu proses penyampaian informasi dari guru kepada siswa ataupun sebaliknya.(Khairani, Majidah, Febrinal, 2011).

Macromedia flash adalah platform multimedia dan perangkat lunak yang digunakan untuk animasi, game dan aplikasi pengayaan internet yang dapat dilihat, dimainkan, dan dijalankan di Adobe Flash Player. (Fahmi, 2013). Macromedia Flash adalah perangkat lunak yang dipakai para professional web (web designer) untuk menghasilkan jaringan internet. Selain itu sudah tersedia sarana untuk membuat program menggunakan Action Script (Fitriasari \& Kartikasari, 2021). Penggunaan macromedia flash sebagai media pembelajaran, bermanfaat bagi guru sebagai alat bantu dalam menyiapkan bahan ajar dan menyelenggarakan pembelajaran. Media ini dapat memancing stimulus siswa agar dapat memanipulasi konsep-konsep serta dapat mengetahui bentuk nyata konsep matematika yang abstrak (Umam, 2016). Macromedia Flash merupakan teknologi audio-visual seperti teks, gambar, sound, animasi, dan lainnya sehingga dapat menghasilkan prestasi berbasis multimedia yang dapat digunakan dalam proses pembelajaran. Pembelajaran berbasis multimedia dapat menyajikan pembelajaran yang lebih menarik, dan tidak monoton, sehingga siswa terhindar dari kejenuhan dan bosan dalam proses pembelajaran. 

pada Mata Pelajaran Matematika di Sekolah Dasar - Ari Aprilia Dwiana, Angela Samosir, Nauli Tama Sari, Nur Awalia, Aan Budiyono, Molli Wahyuni, Masrul

DOI: https://doi.org/10.31004/basicedu.v6i1.1669

Kreativitas merupakan kemampuan seseorang untuk menciptakan sesuatu yang baru berupa gagasan maupun karya nyata yang relatif berbeda dengan apa yang telah ada. Kreativitas sebagai kemauan untuk menciptakan sesuatu yang baru sebagai kemampuan memberikan gagasan baru yang dapat diterapkan dalam pemecahan masalah atau sebagai kemapuan utnuk melihat hubungan baru antara unsure yang sudah ada sebelumnya (Huda \& Munastiwi, 2020). Kreativitas adalah kemampuan yang mecerminkan kelancaran, keluwesan dalam berpikir setelah kemampuan untuk mengelaborasi sebuah gagasan. Kreativitas merupakan proses memicu ide-ide dan merealisasikannya dalam bentuk produk nyata yang berkesesuaian dan memiliki kualitas yang tinggi (Kartini \& Sujarwo, 2014). Kreativitas sebagai keseluruhan kepribadian merupakan hasil dari interaksI dengan lingkungannya. Lingkungan sebagai temapat berinterkasi dapat mendukung berkembangnya kreativitas, tetapi ada juga yang menghambat berkembangnya kreativitas individu (Prameswara, 2018). Berdasarkan karakteristik anak dan dunianya dapat diketahui bahwa perkembangan anak serta dalam mengembangkan pemahaman dan kreativitas anak masih membutuhkan bantuan-bantuan dari guru (Made Ayu Suryaningsih et al., 2011). Salah satu cara untuk meningkatkan kreativitas siswa dapat dilakukan dengan cara memilih metode atau pendekatan yang sesuai dengan karakteristik mata pelajaran (Alamsyah, 2016).

Matematika merupakan ilmu yang diajarkan pada setiap jenjang pendidikan, diharapkan dapat memberikan sumbangan dalam rangka mengembangkan kemampuan berpikir secara kritis, sistematis, logis, kreatif, dan bekerja sama secara efektif (Crismono, 2017). Matematika adalah ilmu yang mempelajari tentang bilangan dan ruangan yang bersifat abstrak. Sehingga untuk menunjang kelancaran pembelajaran di samping pemilihan metode yang tepat juga perlu digunakan suatu media pembelajaran yang sangat berperan dalam membimbing abstraksi siswa (Wulandari et al., 2019). Matematika merupakan salah satu disiplin ilmu yang mempunyai peranan penting dalam kehidupan manusia diantaranya sebagai alat pemecahan masalah baik itu dalam permasalahan sederhana sampai pada permasalahan yang lebih rumit. Matematika juga mempersiapkan siswa agar dapat menggunakan matematika dan pola piker matematis dalam kehidupan sehari-hari dalam mempelajari berbagai ilmu pengetahuan (Masykur et al., 2017).

\section{METODE PENELITIAN}

Metode penelitian yang digunakan dalam metode ini adalah penelitian deskriptif kualitatif, yaitu metode penelitian yang berusaha membuat deskripsi dari fenomena yang diselidiki dengan cara melukiskan dan mengklasifikasikan karakteristik fenomena tersebut secara naratif, faktual dan cermat, kemudian menuangkannya dalam bentuk kesimpulan. Populasi dalam penelitian ini adalah siswa SD Negeri 013 Rambah dan sampel dalam penelitian ini adalah siswa kelas IV SD Negeri 013 Rambah.

Sumber data dalam penelitian ini yaitu sumber data primer dan sumber data sekunder. Untuk mengumpulkan data dari lapangan dalam kegiatan penelitian ini penulis menggunakan metode observasi, metode interview, dan metode dokumentasi. Data primer (data utama) yaitu sumber data yang diperoleh dengan metode observasi, kuesioner dan wawancara. Terkait dalam penelitian ini yang menjadi sumber data yaitu guru Matematika dan siswa kelas IV. Sedangkan data sekunder (data tambahan) yaitu sumber data yang diperoleh dari dokumentasi. Dokumentasi berupa data-data yang diperoleh dari SD Negeri 013 Rambah mengenai profil sekolah, keadaan guru, keadaan siswa, sarana dan prasarana serta dari foto-foto kegiatan belajar. 

pada Mata Pelajaran Matematika di Sekolah Dasar - Ari Aprilia Dwiana, Angela Samosir, Nauli Tama Sari, Nur Awalia, Aan Budiyono, Molli Wahyuni, Masrul

DOI: https://doi.org/10.31004/basicedu.v6i1.1669

\section{HASIL DAN PEMBAHASAN}

Pada bab ini penulis akan membahas tentang pengolahan data hasil jawaban siswa yang diperoleh dari hasil jawaban kuesioner yang diberikan kepada responden. Kuesioner ini berjumlah 15 pertanyaan yang diberikan kepada siswa kelas IV SD Negeri 013 Rambah. Pertanyaan tersebut memiliki tiga alternatif jawaban pilihan ganda, sehingga kuesioner ini bersifat semi terbuka, artinya responden diminta untuk memberikan pendapat dan jawaban berdasarkan pilihan yang diberikan. Sebelum menganalisis data, data tanggapan responden terhadap kuisioner yang diajukan terlebih dahulu diolah dengan menggabungkan hasil tanggapan berdasarkan alternatif tanggapan yang tersedia, kemudian dihitung berdasarkan persentase dan kemudian dimasukkan datanya. Untuk mencari nilai prosentase penulis menggunakan rumus sebagai berikut:

$$
\mathrm{P}=\frac{F}{N} \times 100
$$

Keterangan:

$\mathrm{P}=$ Prosentas

$\mathrm{F}=$ Jumlah responden

$\mathrm{N}=$ Jumlah Sampel

Hasil perhitungan tersebut dimasukkan ke dalam tabel hasil kuesioner. Selain mengolah data yang diterima, tabulasi ini juga memudahkan proses analisis data global dan memberikan interpretasi dan kesimpulan. Setelah memperoleh gambaran umum dari tabel-tabel yang disajikan, data angket dianalisis dan diinterpretasikan berdasarkan masing-masing item, kemudian ditarik kesimpulan berdasarkan hasil tanggapan dengan persentase tertinggi. Langkah selanjutnya adalah menganalisis elemen data umum yang terkait dengan hasil wawancara dan observasi. Adapun pengolahan data tersebut hasilnya dapat dilihat pada tabel di bawah ini sebagai berikut :

Tabel Pengolahan Data Hasil Jawaban Kuesioner Siswa-Siswi kelas IV SD Negeri 013 Rambah

\begin{tabular}{|c|c|c|c|c|c|c|c|c|}
\hline \multirow{2}{*}{$\begin{array}{l}\text { NomerIt } \\
\text { em }\end{array}$} & \multirow{2}{*}{$\begin{array}{l}\text { JumlahSa } \\
\text { mpel }\end{array}$} & \multirow[b]{2}{*}{$\mathbf{A}$} & \multirow[b]{2}{*}{$\%$} & \multirow[b]{2}{*}{ B } & \multicolumn{3}{|c|}{ Hasil } & \multirow{2}{*}{$\begin{array}{l}\text { Total } \\
\%\end{array}$} \\
\hline & & & & & $\%$ & $\mathbf{C}$ & $\%$ & \\
\hline 1 & 25 & 12 & 48 & 5 & 20 & 8 & 32 & 100 \\
\hline 2 & 25 & 1 & 4 & 20 & 80 & 4 & 16 & 100 \\
\hline 3 & 25 & 12 & 48 & 10 & 40 & 3 & 12 & 100 \\
\hline 4 & 25 & 3 & 12 & 17 & 68 & 5 & 20 & 100 \\
\hline 5 & 25 & 6 & 24 & 15 & 60 & 4 & 16 & 100 \\
\hline 6 & 25 & 13 & 52 & 5 & 20 & 7 & 28 & 100 \\
\hline 7 & 25 & 18 & 72 & 3 & 12 & 4 & 16 & 100 \\
\hline 8 & 25 & 3 & 12 & 18 & 72 & 4 & 16 & 100 \\
\hline 9 & 25 & 5 & 20 & 18 & 72 & 2 & 8 & 100 \\
\hline 10 & 25 & 10 & 40 & 8 & 32 & 7 & 28 & 100 \\
\hline 11 & 25 & 11 & 44 & 12 & 48 & 2 & 8 & 100 \\
\hline 12 & 25 & 4 & 16 & 5 & 20 & 16 & 64 & 100 \\
\hline 13 & 25 & 7 & 28 & 4 & 16 & 14 & 56 & 100 \\
\hline 14 & 25 & 6 & 24 & 4 & 16 & 15 & 60 & 100 \\
\hline 15 & 25 & 2 & 8 & 20 & 80 & 3 & 12 & 100 \\
\hline
\end{tabular}

Dari penjabaran dan analisis data yang penulis peroleh dari siswa kelas IV SD Negeri 013 Rambah, dapat disimpulkan bahwa siswa terkadang mengalami kesulitan dalam belajar matematika apalagi ketika guru mengajar hanya dengan metode ceramah, sangat bosan dan lebih suka mengobrol dan bermain dengan teman dengan tidak memperhatikan materi yang dijelaskan oleh guru. 

pada Mata Pelajaran Matematika di Sekolah Dasar - Ari Aprilia Dwiana, Angela Samosir, Nauli Tama Sari, Nur Awalia, Aan Budiyono, Molli Wahyuni, Masrul

DOI: https://doi.org/10.31004/basicedu.v6i1.1669

Siswa merasa sangat tertarik jika dalam proses belajar mengajar guru menggunakan alat bantu berupa media pembelajaran, khususnya media pembelajaran macromedia flash. Macromedia flash adalah sebuah media yang menggabungkan tekhnologi audio-visual seperti teks, gambar, sound, animasi dan lainnya sehingga siswa lebih mudah dalam memahami pelajaran yang disampaikan guru. Media pembelajaran dapat membangkitkan kreativitas siswa dalam belajar dengan tujuan agar siswa dapat berperan aktif di dalam proses belajar mengajar khususnya dalam pelajaran matematika. Hal ini berdasarkan pada analisis data pada item nomor 1, 3, 6, 10, 11, 12, 13, 14, dan 15. Sedangkan jika dilihat dari faktor tidak ketertarikan siswa dilihat pada hasil jawaban kuesioner item nomer 4, 5, 7, 8 dan 9 yaitu siswa yang menyatakan kurang tertarik terhadap media pembelajaran yang digunakan guru saat ini dalam proses belajar mengajar.

Metode pembelajaran yang digunakan guru tidak sesuai dengan sarana pembelajaran yang digunakan guru. Guru hanya mengandalkan buku cetak dan buku teks dalam proses belajar mengajar, sebagai selingan guru menggunakan lembar kerja dan benda asli dalam proses belajar mengajar sehingga siswa kurang aktif dan kreatif dalam pembelajaran karena tidak memahami materi yang diajarkan guru.

Dari beberapa analisis data observasi, wawancara, dokumentasi dan tanggapan terhadap angket yang di terima penulis, dapat disimpulkan bahwa minat siswa terhadap media pembelajaran yang digunakan guru dalam proses belajar mengajar, khususnya macromedia flash sangat besar. Menggunakan macromedia flash membuat pelajaran lebih mudah dipahami Karena tampilannya yang menarik dipadukan dengan gambar animasi, audio, dan teks yang mudah di cerna oleh siswa.

Kesimpulan ini didukung oleh hasil wawancara penulis dengan siswa SD Negeri 013 Rambah yaitu Afirazuita dan Fajar Ramadhani yang menyatakan bahwa "belajar menggunakan media pembelajaran sangat menyenangkan dan tidak membosankan karena media macromedia flash menarik dan lebih mudah dipahami, sehingga kreativitas belajar akan meningkat. Erhana Isyabela menambahkan pendapat di atas, menjelaskan bahwa "sebelum menggunakan media pembelajaran macromedia flash pembelajaran sangat membosankan, saat guru mengajar di kelas siswa lebih banyak bermain dan mengobrol dengan teman dari pada memperhatikan penjelasan guru, setelah menggunakan pembelajaran media sudut pandangakan fokus pada media yang digunakan oleh guru agar topik lebih mudah dipahami”.

Berdasarkan hasil wawancara di atas dapat dianalisa bahwa siswa sangat tertarik dengan media pembelajaran macromedia flash yang digunakan guru, siswa lebih mudah memahami topik yang disampaikan oleh guru menggunakan media dibandingkan guru yang hanya sekedar ceramah atau bercerita. Dengan menggunakan macromedia flash perbedaan siswa akan semakin diperhatikan guna meningkatkan kreativitas belajar siswa.

\section{KESIMPULAN}

Dengan penggunaan media pembelajaran berbasis Macromedia Flash, sebagian besar siswa sangat tertarik dan menyukai media pembelajaran yang digunakan oleh guru khususnya media pembelajaran macromedia flash. Macromedia Flash membuat materi pembelajaran lebih mudah dipahami siswa karena tampilannya yang menarik, perpaduan audio visual, animasi, dan teks untuk membantu siswa lebih aktif dalam belajar dan meningkatkan kreativitas siswa.

\section{DAFTAR PUSTAKA}

Alamsyah, N. (2016). Penerapan Pendekatan Saintifik Untuk Meningkatkan Kreativitas Dan Hasil Belajar Siswa Dalam Mata Pelajaran Ipa Nur Alamsyah Abstrak. Jurnal Pendidikan, 1(5), 81-88.

Crismono, P. C. (2017). Pengaruh Outdoor Learning Terhadap Kemampuan Berpikir Kritis Matematis Siswa 

pada Mata Pelajaran Matematika di Sekolah Dasar - Ari Aprilia Dwiana, Angela Samosir, Nauli Tama Sari, Nur Awalia, Aan Budiyono, Molli Wahyuni, Masrul DOI: https://doi.org/10.31004/basicedu.v6i1.1669

The Influence Of Outdoor Learning On The Mathematical Critical Thinking Skills Of Students. Junal Pendidikan Matematika Dan Sains, 4(2), 106-113. Http://Journal.Uny.Ac.Id/Index.Php/Jpms Jurnal

Fahmi, S. (2013). Pengembangan Multimedia Macromedia Flash Dengan Pendekatan Kontekstual Dan Keefektifannya Terhadap Sikap Siswa Pada Matematika. Agrisains, 5(2), 1-109.

Fitriasari, A., \& Kartikasari, R. D. (2021). Penerapan Model Pembelajaran Snowball Throwing Berbantuan Macromedia Flash Dalam Meningkatkan Keterampilan Menulis Teks Eksposisi. Imajeri: Jurnal Pendidikan Bahasa Dan Sastra Indonesia, 04(1), 17-25. Https://Doi.Org/10.22236/Imajeri.V4i1.6758

Heri Setiawan, R., \& Harta, I. (2014). Pengaruh Pendekatan Open-Ended Dan Pendekatan Kontekstual Terhadap Kemampuan Pemecahan Masalah Dan Sikap Siswa Terhadap Matematika. Jurnal Riset Pendidikan Matematika, 1(2), 241. Https://Doi.Org/10.21831/Jrpm.V1i2.2679

Huda, K., \& Munastiwi, E. (2020). Strategi Orang Tua Dalam Mengembangkan Bakat Dan Kreativitas Anak Di Era Pandemi Covid-19. Jurnal Pendidikan Glasser, 4(2), 80 Https://Doi.Org/10.32529/Glasser.V4i2.670

Hutomo, B. P. M. (2015). Penerapan Media Interaktif Berbasis Macromedia Flash Pada Kompetensi Dasar Memelihara Transmisi Otomatis Dan Komponennya Untuk ( The Application Of Macromedia Flash Based Interactive Media On The Basic Competence Of Maintain Automatic Transmission And Com. 15(2), 78-81.

Johariyah, S., \& Resti, Y. (N.D.). Penerapan Strategi Pembelajaran Aktif Tipe The Power Of Two Dengan Media Gambar Untuk Meningkatkan Kreativitas Dan Prestasi Belajar Bahasa Indonesia Tingkat Mi. 193-204.

Kartini, K., \& Sujarwo, S. (2014). Penggunaan Media Pembelajaran Plastisin Untuk Meningkatkan Kreativitas Anak Usia. Jurnal Pendidikan Dan Pemberdayaan Masyarakat, 1(2), 199. Https://Doi.Org/10.21831/Jppm.V1i2.2689

Khairani, Majidah, Febrinal, D. (2011). Pengembangan Media Pembelajaran Dalam Bentuk Macromedia Flash Materi Tabung Untuk Smp Kelas Ix. Elex Media, 10(2), 95-102.

Lasmiyatun, \& Saptaningrum, E. (2019). Implementasi Macromedia Flash Dengan Model Pembelajaran Kooperatif Tipe Think Pair Share Sebagai Upaya Peningkatan Hasil Belajar Siswa. 1(1), 105-112.

Made Ayu Suryaningsih, N., Made Elia Cahaya, I., \& Endah Poerwati, C. (2011). Implementasi Pembelajaran Inkuiri Terbimbing Berbasis Permainan Dalam Meningkatkan Kreativitas Anak Usia Dini. 5(2).

Masykur, R., Nofrizal, N., \& Syazali, M. (2017). Pengembangan Media Pembelajaran Matematika Dengan Macromedia Flash. Al-Jabar: Jurnal Pendidikan Matematika, 8(2), 177-186. Http://Ejournal.Radenintan.Ac.Id/Index.Php/Al-Jabar/Article/View/2014/1564

Nurhayati, L., Martini, K., \& Redjeki, T. (2013). Peningkatan Kreativitas Dan Prestasi Belajar Pada Materi Minyak Bumi Melalui Penerapan Model Pembelajaran Problem Based Learning (Pbl) Dengan Media Crossword. Jurnal Pendidikan Kimia Universitas Sebelas Maret, 2(4), 151-158.

Nursofi, Muhammad Faiq, A. B. (2011). Penerapan Media Pembelajaran Berbasis Macromedia Flash Untuk Meningkatkan Hasil Belajar Teknik Pelapisan Dan Korosi. Jurnal Pendidikan Teknik Mesin, 11, 3-8.

Prameswara, A. P. (2018). Penerapan Media Pembelajaran Macromedia Flash Dalam Meningkatkan Kreativitas Siswa Pada Mata Pelajaran Pai Di Smp Muhammadiyah 2 Kalirejo Lampung Tengah. Skripsi, 14.

Rahmat Dian, D., Jasman, Irzal, \& Adri, J. (2020). Penerapan Multimedia Interaktif Menggunakan Macromedia Flash Terhadap Hasil Belajar Materi Las Oksi-Asetilen Pada Siswa Smk Jurusan Teknik Las. 2(4), 117-121.

Rusnilawati, R. (2016). Pengembangan Perangkat Pembelajaran Matematika Bercirikan Active Knowledge Sharing Dengan Pendekatan Saintifik Kelas Viii. Jurnal Riset Pendidikan Matematika, 3(2), 245. 
505 Penerapan Media Pembelajaran Berbasis Macromedia Flash dalam Meningkatkan Kreativitas Siswa pada Mata Pelajaran Matematika di Sekolah Dasar - Ari Aprilia Dwiana, Angela Samosir, Nauli Tama Sari, Nur Awalia, Aan Budiyono, Molli Wahyuni, Masrul

DOI: https://doi.org/10.31004/basicedu.v6i1.1669

Https://Doi.Org/10.21831/Jrpm.V3i2.10633

Umam, K. (2016). Pengaruh Menggunakan Software Macromedia Flash 8 Terhadap Hasil Belajar Matematika Siswa Kelas Viii. Kalamatika Jurnal Pendidikan Matematika, $1(1), \quad 84$. Https://Doi.Org/10.22236/Kalamatika.Vol1 no1.2016pp84-92

Wulandari, T. J., Siagian, S., \& Sibuea, A. M. (2019). Pengembangan Media Pembelajaran Dengan Aplikasi Macromedia Flash Pada Mata Pelajaran Matematika. Jurnal Teknologi Informasi \& Komunikasi Dalam Pendidikan, 5(2), 195-210. Https://Doi.Org/10.24114/Jtikp.V5i2.12598 